\title{
The Challenges of Challenge.Gov: Adopting Private Sector Business Innovations in the Federal Government
}

\author{
Ines Mergel \\ Syracuse University \\ iamergel@syr.edu
}

\author{
Stuart I. \\ Bretschneider \\ Syracuse University \\ sibretsc@maxwell.syr.edu
}

\author{
Claudia Louis \\ Syracuse University \\ louis.claudia@gmail.com
}

\author{
Jason Smith \\ Syracuse University \\ Jdsmit15@syr.edu
}

\begin{abstract}
As part of the Open Government Initiative in the U.S. federal government, the White House has introduced a new policy instrument called "Challenges and Prizes", implemented as Challenge.gov that allows federal departments to run Open Innovation (OI) contests. This initiative was motivated by similar OI initiatives in the private sector and to enhance innovativeness and performance among federal agencies. Here we first define the underlying theoretical concepts of OI, crowdsourcing and contests and apply them to the existing theory of publicness and the creation of public goods. We then analyze over 200 crowdsourcing contests on CHALLENGE.GOV and conclude that federal departments and agencies use this policy instrument for four different purpose: awareness, service, knowledge and technical solutions. We conclude that Challenge.gov is currently used as an innovative format to inform and educate the public about public management problems and less frequently to solicit complex technological solutions from problem solvers.
\end{abstract}

\section{Introduction}

As part of the Open Government Initiative in the U.S. federal government, the White House has introduced a new policy instrument called "Challenges and Prizes" that is based on existing experiences and practices in the corporate sector. This initiative was heavily motivated by the success of such efforts conducted in the private sector. The objective of these efforts is to enhance the "innovativeness" of the federal government in an effort to enhance performance.

The purpose of this paper is to clarify concepts surrounding this initiative and provide a theoretical lens for understanding how this and similar efforts are likely to differ from those conducted by the private sector. The framework developed will be applied to one of the major U.S. federal government attempts to apply crowdsourcing contests to enhance innovation; CHALLENGE.GOV. A significant amount of both theoretical and empirical work has identified differences in both how government and business manage as well as how their products and services differ [1].
We begin by clarifying the core concepts of OI, crowdsourcing and contests and follow with a number of examples used by the private sector aimed at improving organizational performance through crowdsourcing contests. Next we review the literature on how public and private organizations differ and identify how crowdsourcing contest efforts are likely to be applied by government. We then empirically examine over 200 crowdsourcing contests implemented by CHALLENGE.GOV and find how well our theoretical prediction match practice. Finally we conclude with a discussion on how government is likely to continue to implement crowdsourcing contests with some suggestions on how to improve their effectiveness.

\section{OI, crowdsourcing and contests}

The concepts of OI, crowdsourcing and online contests to create innovations are oftentimes interchangeably used in the current discussion about innovative approaches to renew public service. The basis of OI is crowdsourcing, a concept that describes the process supported by technology to solicit input from a large number of distributed people to solve problems that an organization cannot solve on its own [see for example 2,3]. The best known example is Wikipedia, which was built on the willingness of individual citizens to contribute their knowledge to the open knowledge sharing platform. Millions of volunteer contributors have built a free encyclopedia with over 3.5 million articles in English and translations into several hundred other languages [4]. In comparison to the existing printed Encyclopedia Britannica, which employed over 4,000 experts and editors to continuously update the paper version of the encyclopedia, Wikipedia's citizen experts crowdsource their collective knowledge, correct each other's entries within seconds [5]. Another indirect form of using the wisdom of the crowd is reCaptcha that can identify whether a user is a human being or a computer during sign-in procedures on websites. Humans have to identify distorted text that in turn is used to help digitize books, newspapers or radio shows [6].

Similar approaches are used by corporate sector organizations whose research and development 
departments are opening their internal innovation process to the public - or selected outside experts - to collaborate with them on problems that they cannot solve internally $[7,8]$. Firms are no longer restricted solely to their internal ideas, instead embrace input from a variety of stakeholders such as suppliers, customers, the general public and elite problem solvers [9]. This innovation trend has been further enhanced by the use of the Internet to increase awareness for OI campaigns, but also access to and distribution of information from geographically dispersed experts who were previously not part of the innovation creation process [7].

In the private sector, OI processes are used to find creative solutions for problems that the organization itself was not able to solve on its own [10], to innovate at a faster rate and with potentially lower risk [11], or to discover new products and markets that were not explored before [9]. Oftentimes these OI initiatives are tied to a contest, such as a design contests and a panel of judges then reviews and awards a financial reward to the selected problem solver.

OI initiatives allow firms to innovate by tapping into diverse skills and experiences from outside [12]. Solutions are collected in a competitive process to award prizes to winning entries. Other OI initiatives are set up in form of a collaborative process where all entries contribute to the final outcome. As an example, Netflix Prize challenged individuals and teams to design an algorithm to increase the accuracy of the company's personalized movie recommendation system and promised a prize purse of $\$ 1 \mathrm{~m}$ [13]. The movie recommendation system relied on movie ratings from viewers to predict and recommend future movie choices. The use of the innovative algorithm has allowed Netflix to stay competitive in a highly volatile market segment by reaching out to innovators, who were previously not part of the Netflix's own R\&D department.

Similarly, Dell launched a multi-step OI initiative called IdeaStorm to encourage customers to share their ideas for new products or services they would like to see developed by the company [14]. Dell actively encouraged collaboration among problem solvers by allowing the integration of related ideas submitted by different solution providers and extended the competitive process into a collaborative effort.

The toy company Lego, is using an OI approach to solicit design ideas from customers for future products. The creators of projects accepted by the company are rewarded with $1 \%$ of total net sales from the final product [15]. These design contests tap into the customer base and their need for innovations that the company's design team was not able to invent on their own.
Previous research has identified several benefits of engaging stakeholders in these new forms of product design and ideation processes. By actively involving customers as designers into the innovation process, organizations are increasing the satisfaction beyond mere reviews of already existing products. The organizations are able to enhance related customer service activities, are matching sales history with potential future needs and can contribute to the organization's sustainability and viability.

However, not all OI approaches cannot necessarily be labeled crowdsourcing [16]: Problem solvers are not collaboratively working on a solution or a joint final product and are not required to edit each other's solutions. On the contrary, most OI campaigns are set up as competitions or contests with a single winner and even a prize that is paid out or awarded to the winning solution provider. These illustrations from the private sector highlight that much of the discussion surrounding OI lacks some precision. It also seems clear that $\mathrm{OI}$ is the more general notion and makes use of a wide variety of strategies and techniques. For our purposes we will think of OI as a collection of approaches all aimed at generating innovations and enhancing the overall innovativeness of an organization. Concepts like crowdsourcing and contests are used as specific techniques within an OI strategy to achieve innovativeness. It is also useful to note that crowdsourcing and contests are techniques not confined to OI.

\section{Application of OI approaches in the public sector}

OI approaches are used in the public sector to solve public management problems or create innovative public services [17]. As an example, the non-profit organization Code For America collaborates with government open data portals, such as Data.gov or OpenDataPhilly.org to encourage civic hackers in the local technology community to create new mobile phone applications. A contest format is used to invite and engage problem solvers and use public data sets to come up with innovative ideas for the use of data. Another approach is to support ideation and suggestion processes in order to increase the efficiency and effectiveness of public service delivery [18].

Three different approaches can be distinguished: (1) initiatives that are solely soliciting input from citizens; (2) initiatives that are focusing on input provided from employees only; and (3) approaches that combine both audiences, internal government employees and all external stakeholders.

Government OI approaches that are focusing on citizens in clearly identifiable geographic locations (such as a county or city) include for example the 
broadbandvt.org initiative in Vermont. This OI platform is a partner initiative between the Department of Public Services, the UVM Center for Rural Studies, and the Vermont Telecommunications Authority. It provides an online location to run grand challenges and serves as an information and education portal to document progress of broadband diffusion in the state. Maricopa County's Idea Factory for "Rewarding Ideas" initiative or NY city's SimpliCity portal both focus mainly on government employees' ideas to improve the effectiveness and efficiency of government processes and are not open to the public [19]. Some of the existing OI initiatives focus on bringing all stakeholders together on a joint platform. As an example, the city of San Jose has used the Wikiplanning platform to invite feedback on design ideas for the rejuvenation of the city's market place [20]. The multi-step process went beyond mere voting on ideas. Instead, participants were asked to provide detailed steps for the implementation of their ideas, including solutions for the acquisition of necessary resources [21]. All initiatives are designed to bring new information, opinions and innovations into government from stakeholders who otherwise do not have a voice. In the next section of the paper we discuss how government efforts are likely to differ from those conducted by the private sector.

\section{Application of public-private differences and publicness theory and research}

Over the past 50 years a diverse and interdisciplinary literature has developed to provide an explanation as to why public and private organizations are different and secondly to help predict and manage the implications of those differences. The research includes economic theories related to the nature of the produced goods or services [22], ownership characteristics of the organization [23], typologies of differences in management due to sector designation [24], and multi-dimensional models [1]. Recently this literature has also begun to link up with notions of public values as another basis for understanding differences and generating implications to managing public organizations [25]. Along with these theoretical frames there is a great deal of empirical research that attempts to verify the theoretical distinctions and implication.

An important distinction needs to be made before proceeding. We separate political process and actors from formal government organizations and non-elected public managers. Thus online applications of crowdsourcing by elected representatives or candidates for public office are not included in this analysis.

Crowdsourcing as defined above and as popularly implemented in the private sector is about organizational innovation. The core idea is to harness the Internet as a new channel for external input of ideas. To consider how public-private differences and publicness theory may affect innovation, it is useful to think about how innovation generally affects an organization. Many students of organization innovation suggest that innovation operates either on products (and services) or process [26]. From a product/service perspective there are two main outcomes: generation of new products or improvements on existing products. From the process side, the main impact is to effect the production process and hence the cost of producing various goods and services. For our purposes we will lump together the first two since their focus is in new product creations and not on process innovations.

New or improved products/services: How likely is crowdsourcing and OI to lead U.S. federal agencies to create new products or services?

The economic theories of public goods, transactions costs and property right all acknowledge that at its core government produces a set of services typically not produced efficiently by markets. While over time technology has sometimes changed this, it remains true that public goods such as national defense still fit this model. Related to this view is a concept called externalities that in the production and consumption of certain goods benefits and cost occur are not captured in traditional market mechanisms. As a result some goods and services like education and research are produced both by the public and private sector. In the case of education, while markets can match some buyers and sellers on willingness to pay there are specific benefits to ensuring everyone in the society receives some level of education even if they cannot afford it or may choose not to pay for it. In the case of research, public sector research support tends to be of a more basic nature while the private sector focuses on more development-oriented and closer to market ideas. In the case of education if left purely to the market, economic theory predicts underconsumption and the loss of important spillover effects. Similarly, in the case of research left solely to markets they would under-produce basic new knowledge, which typically has no immediate market value. One of the consequent results of these differences is that it is unlikely that new public services are created directly from crowdsourcing activities.

Secondly, publicness and public values theory suggest that political process is instrumental in defining what publicly provided goods are. For example, certain private sector firms produce for private markets and under government contracts. A classic example of this is the aircraft industry. Bozeman used Boeing Aircraft to illustrate this point [1]. At the same time in the U.S. the political process 
has typically been reticent to provide government services which compete with potential private market products and services. In fact government typically tries to use private market organizations to provide innovative public goods or services or outsource the implementation process to more cost-effective providers. The example of Boeing and other defense and space program contractors illustrates this point. This is an area where crowdsourcing might have a role in generating or to aiding the generation of new products or services. This is because the market is a monopsony or single entity of the U.S. federal government. Thus in this context a government agency actions are associated with new products in defense and space may be a relevant focus, though the makeup of the crowd becomes particularly relevant for these types of highly technical new products. We expect that crowdsourcing will then supplement other mechanisms used by government to obtain innovative solutions for research- and defense-related needs like contracting and bidding approaches.

A second type of product that many government agencies provide is information. This can be about healthy behaviors such as food qualities, health problems related to smoking, crime incident information and even current traffic information including bus schedules. These changes while designed to improve the well-being of individuals are also typically done in areas that have a strong spillover effect to other areas like health, education and science.

In this arena we have seen a number or approaches where crowdsourcing tied to the use of prizes have led to a number new products, such as online and mobile apps. One early illustration of this was the Apps for Democracy program run for the city of Washington, DC. Here changing technology has enabled new types of apps and the historic role of government in collecting, summarizing and displaying large amounts of data makes government a natural producer.

Process improvement and cost savings: How likely is crowdsourcing and OI likely to lead US Federal agencies to generate process improvements or cost savings?

As noted in the previous section, the potential role for government organizations and non-elected public managers to produce innovative goods and services is significantly constrained by the role of political actors and processes in a democracy. The types of new products and services obtained through a crowdsourcing approach are likely limited to research, information and information managing applications. In each of these areas crowdsourcing can change, enhance or revise existing products and services. Not surprisingly all of these applications are informationintensive. Producing, organizing, and distributing information has always been a main element of government services and a core element of the economic theories of public goods. Technological changes in information and communications management are often at the root of changing services from public to private provision.

Implementation and service delivery of many governmental services also reflects the information intensity of goods and increasing use of ICT in general. More and more, government organizations make use of the Internet to collect data and deliver services. Government-run websites have become a major part of the service delivery system. Thus crowdsourcing is likely to provide a tool for innovation in service delivery and the process of providing services. As noted above some products like mobile phone apps are as much about the delivery of service process as they are about creating a product or a tool for increasing transparency and public awareness of available public sector data.

Another major type of outcome government produces are regulations. Regulations typically go through three distinct phases; design and development, implementation, and evaluation, review and revision (or elimination). Most regulatory design processes include input from experts and citizens on potential impacts of regulatory rules. It is likely that crowdsourcing with and without contest elements can be used in the process of designing and evaluating regulations. Thus the immediate effect of these new approaches to OI can be felt in the process of engaging experts and citizens at both the design stage and evaluation stage. Legally the creation process for binding rules is either directly through legislative action or indirectly through delegated authority to administrators. It is, though, possible that over time regulations could be ultimately voted on through crowdsourcing processes, but not without a number of important procedural safeguards to protect minority rights, here defined in part by those without adequate access to a purely online process. Hence we expect to see crowdsourcing applications that enhance forms of citizen participation in a wide variety of regulatory review and development. Many efforts in government associated with outreach for measuring the quality of a service or delivery process can be an area where crowdsourcing might provide useful innovative response for government. This suggests applications of crowdsourcing to evaluate citizen satisfaction with a wide range of services and practices by government.

\section{The context: "Challenges and Prizes" as part of the Open Government Initiative}

On the federal government level, OI approaches were institutionalized as part of the ongoing Open 
Government Initiative. In 2007, the U.S. Congress passed the "America Creating Opportunities to Meaningfully Promote Excellence in Technology, Education, and Science Reauthorization Act". The objective of the Act is "to invest in innovation through research and development, to improve the competitiveness of the United States" [27]. The Act gives agencies authority to use prize competitions as a policy instrument to "spur innovation, solve tough problems, and advance their core missions". The Act outlines the legal and operational framework under which Prizes and Challenges have to be implemented by federal agencies. It includes issues such as types of challenges, participant eligibility, government liability, intellectual property and reporting guidelines. The General Services Administration (GSA) serves as the central agency responsible for providing administrative assistance to agencies.

In March 2010 the Office of Management and Budget provided additional instructions for the use of Challenges and Prizes [28]: Agencies were urged to increase their capacity to support, design and manage prizes, proactively identify and address any legal, regulatory or technical barriers hindering the implementation of these challenges. In response to the OMB directive, GSA selected ChallengePost.com as the basis for the online platform Challenge.gov. The platform is designed to facilitate the public broadcasting of agencies' call to help solve public management problems encountered in the U.S. federal government and provides a channel to collect solutions from citizens. The submitted solutions remain in the public domain and allow other users of the platform to comment or vote on the entries. Combinations of monetary and non-monetary awards are used to incentivize submissions. We see Challenge.gov as a form of OI by opening the boundaries of agencies to allow external problem solvers submit solutions and it uses a combination of crowdsourcing approaches and contests.

After two years of operation the platform generated over 200 challenges submitted by 47 agencies for a wide range of national issues such as health, veterans' services, and employment. Challenge.gov was exclusively aimed at government agencies and organizations principally managed and operated by civil servants. This is particularly relevant since political action is typically the basis for defining public goods or services and while political actors take input on these decisions from public managers and civil servants, their main focus is on crowdsourced citizen input.

However, it is unclear how OI as a practice adopted from the private sector can be successfully implemented in the public sector given the previously reviewed publicness character of government interactions and the provision of goods and services. We focus our attention on the publicly posted problem statements on Challenge.gov. The main research question of this paper is therefore: Can crowdsourcing that is successfully adopted in the private sector be used in the public sector and for what types of uses does it make the most sense?

\section{Data collection and measurement}

For challenges hosted on Challenge.gov all data from announcement, submissions and judging, to prize awards are publicly available on the platform. Some agencies use the platform to announce their own contests and point the problem solvers to external sites. The non-standard layout of these external sites led to many instances of missing or difficult to locate data. For missing data, Internet searches were conducted in order to locate related media announcements and articles about those projects. While contest descriptions followed the same general format, there is variation in the level of detail provided for each project. Consequently, we were unable to obtain some data for some of the challenges.

Data collection took place in two phases. The first phase occurred in January of 2012 and yielded data on 143 challenges that had been posted on the site from its launch in September 2010 through the end of December 2011. Initial steps involved browsing through the list of challenges looking for repetitions and common themes to help identify common attributes, which could be used in the classification process. A link to more information provided in-depth narrative description for each challenge such as project backgrounds, objectives, as well as submission and judging details. The data were both of qualitative, such as the project description and objectives, as well as of quantitative nature, such as prize value, contest dates and number of submissions. The second phase of data collection took place in September of 2012 and yielded an additional 60 federal challenge projects, bringing the total number of projects to 203. The second phase was coded a few months after the completion of the first phase using the codes developed during the first phase. Agreement and stability of codes from one phase once applied to phase two demonstrated reliability of codes.

The key variables coded as part of the data collection effort include submission type, objectives or purpose, and target audience. The classification process began after the first phase of data collection was complete and used a combination of the inductive and intuitive approach. The inductive approach involves empirical observations, while the intuitive approach relies on the researcher's understanding and 
perceptions of the categories. Text describing project goals and objectives were examined and coded based on the format of submissions required from users. This process resulted in six major challenge submission types: creativity, software applications, research proposals and blueprints, nominations, white papers, and a catch-all 'other' category. In general these categories represent different types of outcomes and deliverables. For example, the 'creativity' category includes contest activities such as creating a logo, shooting video footage, painting, etc.

Next we examined each project's objectives to identify patterns emerging from the provided narratives. Four major types of objectives, or challenge purposes, emerged: awareness, knowledge generation, service, and technical solution. Finally, we defined eight target audience: $\mathrm{K}-12$ students, college students, non-profit institutions, experts/professionals, software developers, the general public, entrepreneurs/for-profit businesses, and another catch-all 'other' category.

In addition to data collected on the classification of challenges according to submission type, objectives, and target audience, our dataset includes variables relating to a number of other important challenge characteristics. First, we have data on the umbrella agency or commission that sponsored the challenge. For example, the Office of the National Coordinator for Health Information Technology sponsored several challenges. In this case, we categorized the challenge as being sponsored by the Department of Health and Human Services, to which the Office of the National Coordinator for Health Information Technology belongs. Second, we collected data on whether the prize(s) offered a cash value. For 132 of the 133 challenges with a cash prize, we were able to collect data on the total monetary value in dollars. We also collected data on the challenge voting process used to select winners for contests. Here, we identified four voting categories typically used: expert, public, combination, and other. Expert votes typically consisted of panels of scientists or agency officials, while public votes allowed members of the general public to cast votes (typically via Internet) over a specified time period. Combination votes typically had an expert panel, where each member voted, and a public vote for a ballot of winners developed form the first round of expert voting. If a challenge had a second round of voting, we used the same coding scheme, although only one challenge had a second round of voting. This challenge utilized experts in the second round. We also obtained data on the number of submissions received for 94 challenges and the number of prizes offered for 161 of the challenges. We collapsed this variable to create a dummy variable measuring whether or not the contest had a winnertake-all format or not.

Data on the contest status as of September 2012 identified four contest status categories: closed, open, other, closed with no prize awarded. We also measure the length of time submissions were accepted for the challenge in weeks. We identified which challenges were hosted externally and on what kind of host site. Of the 127 challenges that were externally hosted, we were able to categorize the host site for 123 of them. Finally, we coded data on challenge partnerships and whether or not a previous version of the challenge was held. Table 1 summarizes these data and table 2 provides a breakdown of the challenges by umbrella agency.

Table 1 - Summary Statistics

\begin{tabular}{|c|c|c|c|c|c|}
\hline Variable & $\mathrm{N}$ & Mean & SD & Min & $\begin{array}{l}\mathrm{Ma} \\
\mathrm{x}\end{array}$ \\
\hline Service purpose & 203 & 0.256 & 0.438 & 0 & 1 \\
\hline $\begin{array}{l}\text { Knowledge } \\
\text { generation purpose }\end{array}$ & 203 & 0.143 & 0.351 & 0 & 1 \\
\hline $\begin{array}{l}\text { Technical solution } \\
\text { purpose }\end{array}$ & 203 & 0.202 & 0.402 & 0 & 1 \\
\hline Awareness purpose & 203 & 0.399 & 0.491 & 0 & 1 \\
\hline Software application & 203 & 0.374 & 0.485 & 0 & 1 \\
\hline Proposal/Blueprint & 203 & 0.241 & 0.429 & 0 & 1 \\
\hline Nomination & 203 & 0.044 & 0.206 & 0 & 1 \\
\hline White Paper & 203 & 0.020 & 0.139 & 0 & 1 \\
\hline Creativity & 203 & 0.266 & 0.443 & 0 & 1 \\
\hline $\begin{array}{l}\text { Other submission } \\
\text { type }\end{array}$ & 203 & 0.054 & 0.227 & 0 & 1 \\
\hline $\begin{array}{l}\text { College student } \\
\text { audience }\end{array}$ & 177 & 0.090 & 0.288 & 0 & 1 \\
\hline Nonprofit audience & 177 & 0.017 & 0.129 & 0 & 1 \\
\hline $\begin{array}{l}\text { Experts/Professionals } \\
\text { audience }\end{array}$ & 177 & 0.051 & 0.220 & 0 & 1 \\
\hline $\begin{array}{l}\text { Software developers } \\
\text { audience }\end{array}$ & 177 & 0.232 & 0.423 & 0 & 1 \\
\hline $\begin{array}{l}\text { General public } \\
\text { audience }\end{array}$ & 177 & 0.362 & 0.482 & 0 & 1 \\
\hline $\begin{array}{l}\text { For-profit businesses } \\
\text { audience }\end{array}$ & 177 & 0.040 & 0.195 & 0 & 1 \\
\hline $\begin{array}{l}\text { K-12 students } \\
\text { audience }\end{array}$ & 177 & 0.107 & 0.310 & 0 & 1 \\
\hline $\begin{array}{l}\text { Other type of } \\
\text { audience }\end{array}$ & 177 & 0.102 & 0.303 & 0 & 1 \\
\hline Monetary prize? & 191 & 0.696 & 0.461 & 0 & 1 \\
\hline Monetary prize value & 132 & $\begin{array}{l}4180 \\
487\end{array}$ & $\begin{array}{l}4.35 \mathrm{e} \\
+07\end{array}$ & 200 & $\begin{array}{l}5.0 \\
0 \mathrm{e}+ \\
08\end{array}$ \\
\hline Public primary vote? & 190 & 0.047 & 0.213 & 0 & 1 \\
\hline Expert primary vote? & 190 & 0.832 & 0.375 & 0 & 1 \\
\hline $\begin{array}{l}\text { Combination primary } \\
\text { vote? }\end{array}$ & 190 & 0.116 & 0.321 & 0 & 1 \\
\hline $\begin{array}{l}\text { Other type of primary } \\
\text { vote? }\end{array}$ & 190 & 0.005 & 0.073 & 0 & 1 \\
\hline $\begin{array}{l}\text { Number of } \\
\text { submissions }\end{array}$ & 94 & $\begin{array}{l}84.68 \\
1\end{array}$ & $\begin{array}{l}137.5 \\
48\end{array}$ & 1 & 850 \\
\hline
\end{tabular}




\begin{tabular}{llllll} 
Number of prizes & 161 & 5.857 & 11.98 & 0 & 130 \\
& & & 5 & & \\
Winner-take-all? & 177 & 0.209 & 0.408 & 0 & 1 \\
Closed contest & 195 & 0.708 & 0.456 & 0 & 1 \\
$\begin{array}{l}\text { Open contest } \\
\text { Contest closed with }\end{array}$ & 195 & 0.226 & 0.419 & 0 & 1 \\
no winner & 195 & 0.015 & 0.123 & 0 & 1 \\
Other contest & 195 & 0.051 & 0.221 & 0 & 1 \\
$\begin{array}{l}\text { Duration } \\
\text { Externally hosted? }\end{array}$ & 202 & 3.234 & 4.895 & .03 & 60 \\
Hosted on agency site & 123 & 0.626 & 0.485 & 0 & 1 \\
Hosted on third party & 123 & 0.174 & 0.499 & 0 & 1 \\
site & & & 0.378 & 0 & 1 \\
Hosted on other site & 123 & 0.382 & 0.488 & 0 & 1 \\
type & & & & & \\
$\begin{array}{l}\text { Partnership? } \\
\text { Previous version? }\end{array}$ & 203 & 0.315 & 0.466 & 0 & 1 \\
\hline \hline
\end{tabular}

Table 2. - Number of Challenges Posted by Agency or Commission

\begin{tabular}{|c|c|c|c|}
\hline & Count & Percent & Cum. \\
\hline $\begin{array}{l}\text { Dept. of Health and Human } \\
\text { Services }\end{array}$ & 52 & 25.62 & 25.62 \\
\hline NASA & 21 & 10.34 & 35.96 \\
\hline Envir. Protection Agency & 15 & 7.39 & 43.35 \\
\hline Dept. of Defense & 12 & 5.91 & 49.26 \\
\hline Air Force & 12 & 5.91 & 55.17 \\
\hline Dept. of Transportation & 9 & 4.43 & 59.61 \\
\hline Dept. of Energy & 8 & 3.94 & 63.55 \\
\hline Dept. of Labor & 7 & 3.45 & 67.00 \\
\hline Small Business Admin. & 7 & 3.45 & 70.44 \\
\hline Dept. of Agriculture & 6 & 2.96 & 73.40 \\
\hline Dept. of Education & 6 & 2.96 & 76.35 \\
\hline $\begin{array}{l}\text { Corp. for National and } \\
\text { Community Service }\end{array}$ & 5 & 2.46 & 78.82 \\
\hline General Services Admin. & 4 & 1.97 & 80.79 \\
\hline Dept. of Veterans Affairs & 4 & 1.97 & 82.76 \\
\hline National Science Found. & 4 & 1.97 & 84.73 \\
\hline The White House & 4 & 1.97 & 86.70 \\
\hline Dept. of the Treasury & 3 & 1.48 & 88.18 \\
\hline $\begin{array}{l}\text { Agency for International } \\
\text { Development }\end{array}$ & 3 & 1.48 & 89.66 \\
\hline Dept. of the Interior & 3 & 1.48 & 91.13 \\
\hline $\begin{array}{l}\text { Federal Communications } \\
\text { Comm. }\end{array}$ & 3 & 1.48 & 92.61 \\
\hline Dept. of Commerce & 3 & 1.48 & 94.09 \\
\hline Dept. of State & 2 & 0.99 & 95.07 \\
\hline Navy & 2 & 0.99 & 96.06 \\
\hline $\begin{array}{l}\text { National Archives and } \\
\text { Records Admin. }\end{array}$ & 2 & 0.99 & 97.04 \\
\hline Social Security Admin. & 1 & 0.49 & 97.54 \\
\hline $\begin{array}{l}\text { Consumer Prod. Safety } \\
\text { Comm. }\end{array}$ & 1 & 0.49 & 98.03 \\
\hline Dept. of Homeland Security & 1 & 0.49 & 98.52 \\
\hline $\begin{array}{l}\text { Dept. of Housing and Urban } \\
\text { Dev. }\end{array}$ & 1 & 0.49 & 99.01 \\
\hline Army & 1 & 0.49 & 99.51 \\
\hline Election Assistance Comm. & 1 & 0.49 & 100.00 \\
\hline Total & 203 & 100.00 & \\
\hline
\end{tabular}

\subsection{Data analysis}

Previous we argued that likely innovations from crowdsourcing would be either a new or improved organizational output, or changes to organizational processes. We then applied what we know about public-private organization differences and publicness theory to derive a set of expectations regarding the use of this new policy instrument by U.S. federal government agencies. We suggested that because political process is the main mechanism for defining U.S. federal government services only a few new and improved products would be likely. Thus, we suggested that it seems most likely that federal government agencies will use the platform, not to develop new public services, but to supplement other, more traditional mechanisms used to obtain innovative solutions and achieve cost-savings, such as contracting-out and bidding. We expect this to be particularly true in spaces of pure public good provision, where the federal government is a monopoly producer, such as in areas of basic research, defense, space exploration, and regulation. Second, we argued that many government agencies are expected to provide information to the public using challenges as a vehicle to transport the information in an innovative format. This information is often targeted towards behavioral change and is typically provided in areas, such as health, education, and science. With respect to organizational processes, we argued that the production of public goods is information intensive. Many government outreach efforts are aimed at collecting information to measure and improve the quality of a service or delivery process. The increasing use of the Internet and ICTs makes information collection and dissemination via mobile phone applications and other web-based technologies extremely attractive. Thus, our third expectation is that federal government agencies will frequently make use of crowdsourcing platforms, such as Challenge.gov, to solicit feedback from the public in an effort to measure the quality of a service or delivery process and provide feedback on a wide range of activities.

Recall that we expected federal crowdsourcing efforts to focus not on developing new and innovative public services, but rather to focus on supplementing more traditional mechanisms used to obtain innovative solutions and achieve cost-savings, such as contracting-out and bidding. Is this expectation playing out in practice? In short, these expectations seem to be largely coming to fruition. First, $26 \%$ of challenges came directly from science-oriented agency (e.g. Department of Energy), 13\% from defense agencies and $25 \%$ - from HHS. We note that more than half of these challenges are from science-oriented subunits like the Office of the National Coordination for Health 
Information Technology or the CDC. Thus approximately $53 \%$ of all challenges appear to be initiated by science- or defense-related agencies, which is consistent with some of our expectations.

What sorts of challenges are the S\&T and defense agencies posting? In terms of the purposes of the challenges posted by these agencies, science-oriented and defense agencies appear to be focusing on raising awareness and finding solutions to technical problems their agencies face. For example, 21 of the 53 challenges $(39.62 \%)$ posted by science-oriented agencies focused on raising awareness. Further, 16 of the 53 challenges $(30.19 \%)$ focused on finding technical solutions. Defense agencies on the other hand posted $13(48.15 \%)$ technical solution challenges. With respect to the type of submissions requested, S\&T agencies posted $13(24.53 \%)$ creativity challenges, 16 $(30.19 \%)$ software challenges, and 15 (28.30\%) proposal/blueprint challenges. Other challenge types were far less prevalent. Defense agencies focused primarily on soliciting blueprints/proposals (12 challenges or $44.44 \%$ ). Both types of agencies geared their challenges towards targeting the general public, although $\mathrm{S} \& \mathrm{~T}$ agencies did post a considerable number of challenges targeted towards K-12 students.

Second, we expected many government agencies, especially education-, health-, and science-related agencies, to use crowdsourcing as an approach to provide information to the public in an effort to affect behavioral change. First, recall earlier that scienceoriented agencies seem to be gearing a number of their challenges towards K-12 students and the general public. We found that 21 of the science-oriented agency challenges focused on raising awareness, encouraging creativity, and building software applications. By far the most frequent agency to post on Challenge.gov is HHS, a large agency with many divisions that truly straddles the lines between education, health, and science. HHS had posted a total of $52(25.62 \%)$ challenges on Challenge.gov. This was more than twice as many challenges as the next most frequent poster, NASA. Of the 52 challenges posted by HHS, $24(46.15 \%)$ were devoted to raising awareness. $15(28.85 \%)$ of the HHS challenges were focused on invoking creativity and $16(30.77 \%)$ were targeted towards the general public. Overall, there seems to be a major focus on raising awareness of an issue. A total of $81(39.90 \%)$ of the 203 challenges posted on Challenge.gov were focused on raising awareness. Further, $45(55.55 \%)$ of the 81 challenges that were focused on awareness were posted by either S\&T agencies or HHS. Finally, another department that deserves mentioning here is the Environmental Protection Agency (EPA). Like HHS, the EPA sits at the intersection of education-, health-, and science- related issues. The EPA posted a total of 15 challenges as of September 2012. 13 (86.67\%) of these challenges were focused on raising awareness. Interestingly, the Department of Education, which posted six challenges, only had two focused on awareness.

\subsection{Types of Awareness Challenges}

Awareness challenges all had a mandate to inform, sensitize or educate on a particular topic or issue. The motivation for these challenges can be classified into sensitization, recognition, and behavior change. There were also some challenges categorized as Research and Service with a strong awareness component.

Sensitization: The major motivation for challenges posted in this category is to increase visibility on a particular topic or issue of national importance. These were generally creativity contests aimed at the general public requesting submitters to express their view on the value or impact of the selected topic. For example the National Institute of Food and Agriculture launched "This is MY Agriculture Photo contest" with the aim of increasing visibility on the value of agriculture. Young people were asked to submit photographs to share how they are engaged in agriculture, and how it impacted their communities. Similarly, the EPA "Six Words for the Planet" contest invited people to write six-word essays about the planet or the environment. The objective was to spread awareness on the value of the environment and actively engage the target audience in the issue.

Recognition: The motivation for this category of challenges is to draw national attention to the value of services provided to the community by individuals, groups or government agencies themselves. For example, the Corporation for National and Community Service launched the "AmeriCorps Photo Contest" and the "AmeriCorps Video Contest" to highlight the impact of AmeriCorps projects on communities, as well as the effectiveness and value of AmeriCorps as a promoter of national and community service. The EPA launched the "Presidential Green Chemistry Challenge Awards" and accepted nominations for technologies, which contribute to the protection of the environment through the elimination of hazardous substances from a chemical product or process.

Behavior modification: Beyond drawing attention to certain issues, some challenges aim to influence behavior change in certain segments of the population. Using information and best practice examples they tend to highlight the dangers of current practices or the merits of adopting new ones. Many of these were health-related, including HHS' "Stop Bullying Video Challenge" which asked members of the public to submit videos on how to help children deal with bullying in schools and communities. The Office of 
National Coordinator for Health IT launched the "Managing Meds video challenge" where the public was asked to submit inspiring videos to share how they use technology to manage their medication. The objective was to improve patient health and safety by encouraging individuals to take medication as directed.

As mentioned above there was also an awareness component in some Research and Service related challenges. For example the Department of Transportation launched the "Connected Vehicle Technology Challenge" where members of the public were asked to submit ideas on how wireless technology vehicles can communicate with each other. The motivation was to build awareness of this emerging technology while also gathering public input, which could potentially influence standards and policies to shape the 21 st century transportation industry. This example also illustrates the use of crowdsourcing to provide citizen input to the regulatory process. The annual "Game Day Challenge" hosted by the EPA asked colleges and universities to design plans to reduce environmental wastage on Game Days. One of the primary components was to raise awareness of the impact of wastage on the environment.

The second most popular category of HHS challenges after awareness was dedicated to service delivery involving software applications. Generally these applications were not meant for internal use at the host agency, but were focused on the provision or enhancement of services to institutions and clients under their jurisdiction such as hospitals, clinics, shelters, doctors and patients. Some of the applications provided administrative and institutional support, while others were mobile applications meant to serve individual clients and members of the public. Other objectives of these software development challenges were to create interest among software developers and spur innovation around data, which had recently been made publicly available.

Finally, we expected that federal government agencies would frequently make use of crowdsourcing platforms, such as Challenge.gov, to solicit feedback from the public in an effort to measure the quality of a service or delivery process. In particular, we expected to see crowdsourcing applications that enhance forms of citizen participation in the process of regulatory development and review. To date, this has largely been true.

In sum, our expectations derived public-private differences and publicness theory have largely been met so far. A relatively small number of agencies appear to be making frequent use of the Challenge.gov platform, including the S\&T agencies, defense agencies, and HHS. In the first two years of this new policy instrument, agencies are mainly posting awareness raising challenges with the aim to inform and educate their target audiences about policy changes, implications and prepare them for necessary behavioral changes in the future. As expected S\&T and defense agencies appear to be focusing their challenges primarily towards finding solutions to technical problems, using Challenge.gov as a new vehicle to supplement the existing RFP process. Consequently, the prize money for these types of challenges is exponentially higher than the ones paid out for awareness campaigns.

\section{Discussion and Conclusions}

Much of what we observe might be due to the fact that the President mandated adoption using a top-down strategy. Further, organizations tend to experiment with new innovative technologies and managerial processes in order to learn, so some of our observations may be influenced by those behaviors as well. Clearly, though, a major application for crowdsourcing on Challenge.gov appears to be about identifying and measuring preferences of citizen in response to the new policy instrument. Moreover, given the types of public management problems agencies have posted so far to the public problem solving process, they are in line with previous adoption phases of other types of new technologies. Agencies have mostly invested in simpler forms of problem solving, such as public awareness campaigns such as photo contests. More advanced agencies, such as NASA however are also willing to use an crowdsourcing approach to solicit solutions to complex public management problems that require elite problem solvers with expert knowledge.

This indicates that transferring a private sector practice to the public sector has to be fit into the legal and regulatory constraints in which government organizations are operating. In the private sector, OI and crowdsourcing approaches are designed to move corporations into new market segments, redesign their business models to help them survive in highly competitive marketplaces, adapt to changing stakeholder needs, and to retain and win customers. In the public sector however, changes in service delivery or products by design have to be initiated by a political mandate. Consequently, OI can only contribute to incremental changes or tweaks in existing services and our analysis has shown that the most agencies are using this new policy instrument for informational and educational purposes. It helps them to reach audiences and target groups who might not be aware of the services and subsequently service delivery can be improved.

Rarely do agencies use challenges and contests to create new products and services. Only a minority of the agencies asks for solutions to highly sophisticated 
and complex public management problems such as the technological solutions requested by NASA. This might be due to the fact that these types of problems require elite problem solvers who might be managed and rewarded easier in the framework of a traditional request for proposals (RFP)-process and would not want to see their solutions publicly announced on a web platform.

We conclude from the findings that agencies mainly use Challenge.gov for so-called "low-hanging fruits", those projects which are easy to outsource and implement such as information and education campaigns that help them better understand how to improve their service delivery, but not necessarily the service itself.

Moreover, we conclude that contests are used as a vehicle to collect insights from the public in all phases of the policy making cycle. First, potential or actual impacts of a planned policy change are collected from citizens, which helps to inform implications of changes. Second, after a new policy is implemented the public is informed using Challenge.gov as an outreach mechanism to educate large parts of the citizenry that might not be reached through the traditional channels.

\section{References}

[1] B. Bozeman, All organizations are public: Bridging public and private organizational theories. San Francisco, CA: Jossey-Bass, 1987.

[2] J. P. Howe. (2006, The Rise of Crowdsourcing. Wired Magazine online 14(6). Available: http://www.wired.com/wired/archive/14.06/crowds.html

[3] D. C. Brabham, "Crowdsourcing as a model for problem solving: An introduction and cases," Convergence: The International Journal of Research into New Media Technologies, vol. 14, pp. 75-90, 2008.

[4] J. A. Villarroel, "Strategic Crowdsourcing: The Emergence of Online Distributed Innovation," in Leading Open Innovation, A. S. Huff, K. M. Moeslein, and R. Reichwald, Eds., ed Cambridge, MA: The MIT Press, 2013, pp. 171-200.

[5] C. Schweik, I. Mergel, J. Sanford, and J. Zhao, "Toward Open Public Administration Scholarship," Journal of Public Administration Research \& Theory, vol. 21, pp. i175-i198, 2011.

[6] L. Von Ahn, B. Maurer, C. McMillen, D. Abraham, and M. Blum, "reCAPTCHA: Human-Based Character Recognition via Web Security Measures," Science, vol. 321, pp. 1465-1468, 2008.

[7] H. Chesbrough, Open innovation: the new imperative for creating and profiting from technology. Cambridge, MA: Harvard Business Press, 2003.

[8] A. S. Huff, K. M. Moeslein, and R. Reichwald, Leading Open Innovation. Cambridge, MA: MIT Press, 2013.

[9] H. Chesbrough and A. K. Crowther, "Beyond high tech: early adopters of open innovation in other industries," R\&D Management, vol. 36, pp. 229-236, 2006.
[10] K. R. Lakhani and J. A. Panetta, "The principles of distributed innovation," Innovations: technology, governance, globalization, vol. 2, pp. 97-112, 2007.

[11] B. Chakravorti, "Stakeholder Marketing 2.0," Journal of Public Policy \& Marketing, vol. 29, pp. 97-102, 2010.

[12] P. Whitla, "Crowdsourcing and its application in marketing activities," Contemporary Management Research, vol. 5, pp. 15-28, 2009.

[13] NetFlix.com. (n.d., 3/27/13). Netflix company timeline. Available: https://signup.netflix.com/MediaCenter/Timeline

[14] Dell. (n.d., 06/07/2013). About IdeaStorm. Available: http://www.ideastorm.com/idea2AboutIdeaStorm?v=13 68213488431

[15] Lego. (2013, 06/06/2013). Project Guidelines and House Rules. Available: http://lego.cuusoo.com/guidelines

[16] A. Forte and C. Lampe, "Defining, Understanding, and Supporting Open Collaboration: Lessons From the Literature," American Behavioral Scientist vol. doi: 10.1177/0002764212469362, pp. XXX-XXX, 2013.

[17] A. Collm and K. Schedler, "Managing Crowd Innovation in Public Administration," International Public Management Review, vol. 13, pp. 1-18, 2012.

[18] I. Mergel, "Crowdsourced ideas make participating in government cool again," PA Times, American Society for Public Administration, vol. 34, p. 4 \& 6, 2011.

[19] K. Nadau. (2012, Maricopa County, Ariz., Turns on 'Spigit' for Innovative Ideas. DigitalCommunity.com. Available:

http://www.digitalcommunities.com/articles/MaricopaCounty-Ariz-Turns-on-Spigit-for-Innovation.html

[20] I. Mergel, "Using Wiki's in Government: A guide for using and maintaining wikis in the public sector," IBM, Washington, DC2011.

[21] W. Hanson. (2009, San Jose Launches Wikiplanning. Available: $\quad$ http://www.govtech.com/policymanagement/San-Jose-Launches-Wikiplanning.html

[22] P. A. Samuelson, "The Pure Theory of Public Expenditure," The Review of Economics and Statistics, vol. 36, pp. 387-389, 1954.

[23] A. A. Alchian and H. Demsetz, "Production, Information Costs, and Economic Organization," The American Economic Review, vol. 62, pp. 777-795, 1972.

[24] H. G. Rainey, R. W. Backoff, and e. al., "Comparing Public and Private Organizations," Public Administration Review, vol. 36, pp. 233-244, 1976.

[25] A. de Tocqueville, Democracy in America [De la démocratie en Amérique]. Chicago, IL: The Chicago University Press, 1835 [2000].

[26] E. Von Hippel, Sources of Innovation. Oxford, UK: Oxford University Press, 1988.

[27] America COMPETES Act, t. Congress 110-69, 2007.

[28] The White House, "Guidance on the Use of Challenges and Prizes to Promote Open Government " vol. M-1011 O. o. M. a. Budget, Ed., ed. Washington, DC: Exectuvie Office of the President, 2010. 